\title{
Perioperative cerebral oxygen saturation in neonates with hypoplastic left heart syndrome and childhood neurodevelopmental outcome
}

\author{
George M. Hoffman, MD, ${ }^{\text {a,b }}$ Cheryl L. Brosig, PhD, ${ }^{\text {a,b,c }}$ Kathleen A. Mussatto, BSN, PhD, ${ }^{\text {a,c,d }}$ \\ James S. Tweddell, MD, ${ }^{\mathrm{a}, \mathrm{b}, \mathrm{c}}$ and Nancy S. Ghanayem, MD ${ }^{\mathrm{a}, \mathrm{b}}$
}

Objectives: Neonates with hypoplastic left heart syndrome have significant hemodynamic threats to cerebral perfusion and are at risk of reduced neurodevelopmental performance. We hypothesized that cerebral hypoxia, detectable by near-infrared spectroscopy in the early postoperative period, would be related to later neurodevelopmental performance.

Methods: The study population was a sequential cohort of patients who had undergone stage 1 palliation of hypoplastic left heart syndrome under standard conditions, including neonatal perioperative monitoring with cerebral near-infrared spectroscopy, and who had undergone a neurodevelopmental assessment at age 4 to 5 years. The neonatal demographic and 48-hour perioperative hemodynamic parameters, including cerebral oxygen saturation, were tested for their relationship to 4 domains of neurodevelopmental performance, including visual-motor integration in childhood in univariate and multivariate models. The neurodevelopmental scores were classified as low if less than 85 ( -1 standard deviation) and abnormal if less than 70 ( -2 standard deviations).

Results: For the 51 patients in the surgical cohort, the early survival was $94 \%$, the cumulative survival was $86 \%$, and the neurodevelopmental assessment was completed by $21(48 \%)$ of the survivors, without evidence of an ascertainment bias. At the test age of $56.3 \pm 5.5$ months, the composite neurodevelopmental index, constructed from equally weighted measures in 4 domains, was $97.6 \pm 9.6$, not different from the age-based norms, with 3 of 21 in the low range and none abnormal. The mean visual-motor integration was $93.4 \pm 14$, slightly less than the population norm $(P<.05)$, with 2 of 21 having low scores and 1 abnormal scores. In patients with low to abnormal visual-motor integration, the perioperative stage 1 palliation cerebral oxygenation saturation was significantly lower $(63.6 \pm 8.1$ vs $67.8 \pm 8.1, P<.05)$. Two patients had discrete embolic strokes after their initial hospitalization; the occurrence of late stroke reduced the visual-motor integration performance but was not related to the early cerebral oxygen saturation. Nonlinear relationships of cerebral oxygen saturation to the neurodevelopmental measures found cerebral oxygen saturation thresholds of $49 \%$ to $62 \%$. The hours at a cerebral oxygen saturation less than $45 \%$ and $55 \%$ were related to low visual-motor integration and neurodevelopmental index scores in the univariate and multivariate models. A multivariate model of age and weight at stage 1 palliation, cerebral oxygen saturation, arterial oxygen saturation, cardiopulmonary bypass and deep hypothermic circulatory arrest times, and later stroke predicted visual-motor integration to an important degree $\left(\mathrm{R}^{2}=0.53, P<.001\right)$. The actual and predicted visual-motor integration and neurodevelopmental index were normal when a cerebral oxygen saturation less than $45 \%$ and other risk conditions were avoided.

Conclusions: Neurodevelopmental performance was related to demographic, neonatal perioperative physiologic, and later factors. Perioperative cerebral oxygenation assessed by near-infrared spectroscopy can detect hypoxic-ischemic conditions associated with injury and reduced neurodevelopmental performance and was the most significant physiologic factor identified. These data suggest that efforts to avoid cerebral hypoxia are likely to improve the outcomes in this high-risk population. (J Thorac Cardiovasc Surg 2013;146:1153-64)

\footnotetext{
From the Children's Hospital of Wisconsin, ${ }^{\mathrm{a}}$ Medical College of Wisconsin, ${ }^{\mathrm{b}}$ Herma Heart Center, ${ }^{\mathrm{c}}$ and University of Wisconsin-Milwaukee, ${ }^{\mathrm{d}}$ Milwaukee, Wis.

This study was supported by the Children's Hospital of Wisconsin, the Medical College of Wisconsin, and a grant from the Children's Heart Foundation (N.S.G.). Disclosures: Authors have nothing to disclose with regard to commercial support. Received for publication April 3, 2012; revisions received Nov 23, 2012; accepted for publication Dec 12, 2012; available ahead of print Jan 14, 2013.

Address for reprints: George M. Hoffman, MD, Children's Hospital of Wisconsin, 9000 W Wisconsin Ave, MS \#735, Milwaukee, WI 53226 (E-mail: ghoffman@ mcw.edu).

$0022-5223 / \$ 36.00$

Copyright (c) 2013 by The American Association for Thoracic Surgery

http://dx.doi.org/10.1016/j.jtcvs.2012.12.060
}

Neonates with hypoplastic left heart syndrome and its variants face life-threatening hemodynamic challenges before, during, and after stage 1 palliation (S1P) by the Norwood procedure, related to both patient-specific and treatmentspecific factors. ${ }^{1-3}$ Survival has improved with advances in perioperative techniques, but perioperative mortality remains significant, ${ }^{4}$ with neurodevelopmental (ND) outcomes less than normal in survivors. ${ }^{5-8}$ Mitigation of perioperative hypoxic-ischemic risk has been attributed to intensive monitoring and pharmacologic strategies to control 


$$
\begin{aligned}
& \text { Abbreviations and Acronyms } \\
& \mathrm{CPB}=\text { cardiopulmonary bypass } \\
& \mathrm{CVP}=\text { central venous pressure } \\
& \mathrm{DHCA}=\text { deep hypothermic circulatory arrest } \\
& \mathrm{MRI}=\text { magnetic resonance imaging } \\
& \mathrm{ND}=\text { neurodevelopmental } \\
& \mathrm{NDI}=\text { neurodevelopmental index } \\
& \mathrm{NIRS}=\text { near-infrared spectroscopy } \\
& \mathrm{rSO} \mathrm{C}_{2} \mathrm{C}=\text { regional cerebral oxygen saturation } \\
& \mathrm{S} 1 \mathrm{P}=\text { stage } 1 \text { palliation } \\
& \mathrm{SaO} \\
& \mathrm{SD}=\text { arterial oxygen saturation } \\
& \mathrm{SvO}=\text { standard deviation } \\
& \mathrm{VMI}_{2}=\text { venous oxygen saturation } \\
&
\end{aligned}
$$

hemodynamic responses and improve systemic oxygen delivery. ${ }^{9-13}$ Beyond survival, we have shown that neonatal perioperative hemodynamics, as assessed by venous oxygen saturation $\left(\mathrm{SvO}_{2}\right)$, can predict the ND outcome at age 4 years, ${ }^{14}$ presumably because the $\mathrm{SvO}_{2}$ from the superior vena cava is a proxy measure of cerebral oxygenation. ${ }^{15,16}$ We hypothesized that a more direct measure of brain oxygenation might show a stronger relationship to conditions that cause injury and functional impairment.

Near-infrared spectroscopy (NIRS) provides a measure of organ-specific venous-weighted oxyhemoglobin saturation. ${ }^{17,18}$ Monitoring of brain oxygenation by NIRS is now practical, with accuracy and validity, and comparative data are available for normal and perioperative states for adults and neonates. ${ }^{19-26}$ Cerebral NIRS monitoring allows continuous, quantitative, and noninvasive detection of conditions of cerebral hypoxic risk. ${ }^{27-30}$ Previous work has identified a high risk of cerebral desaturation in the early postbypass and intensive care unit period ${ }^{14,28,31,32}$ and evidence of a relationship between cerebral hypoxia detected by NIRS and the occurrence of brain injury detected by imaging and other measures in the early postoperative period. ${ }^{33-36}$ In the present report, we tested the hypothesis that early perioperative cerebral hypoxia contributes to reduced ND performance by examining the relationship between cerebral oxygenation, as assessed by NIRS after S1P, and measures of ND outcome assessed at age 4 to 5 years.

\section{METHODS \\ Patients}

All neonates undergoing S1P had their perioperative hemodynamic data recorded in standardized format in a prospective database, including $\mathrm{SvO}_{2}$ since 1996, and including cerebral and somatic NIRS starting in 2002. Patients with hypoplastic left heart syndrome who had undergone an initial staged reconstruction using a standardized perioperative management strategy with antegrade cerebral perfusion and intraoperative and postoperative cerebral NIRS monitoring were eligible for ND testing at 4 to 6 years of age as a part of an institutional review board-approved study at the Children's Hospital of Wisconsin. Sequential patients who had received postoperative NIRS monitoring constituted the operative cohort, and all who had completed a ND assessment by September 2009 were included in the primary analysis.

Protocols for neonatal hemodynamic data collection, phenoxybenzamine administration, and ND assessment were followed. The preoperative factors extracted for the present analysis included gestational age and weight at birth, age and weight at S1P, gender, anatomic subtype, prenatal diagnosis, the presence of associated abnormalities or syndrome, and the use of preoperative mechanical ventilation or inotropes. A preoperative high-risk status was defined as gestational age younger than 35 weeks, birthweight less than $2.5 \mathrm{~kg}$, or the presence of noncardiac anomalies. The perioperative variables included cardiopulmonary bypass (CPB) time, circulatory arrest, antegrade cerebral perfusion, shunt type (modified Blalock-Taussig shunt vs right ventricle to pulmonary artery shunt), and the use of extracorporeal membrane oxygenation. Other factors included the need for manual cardiopulmonary resuscitation during the initial hospitalization, interstage events (after discharge from S1P to stage 2), and the occurrence of a neurologic event after S1P.

\section{Clinical Management}

The neonatal perioperative management strategies have been previously described $^{9,13,26,37,38}$ and included preoperative stabilization with prostanoids, intraoperative high-dose opioid and isoflurane-balanced anesthesia, aprotinin, high-flow $\mathrm{CPB}$ to $18^{\circ} \mathrm{C}$ to $20^{\circ} \mathrm{C}$ using pH-stat blood gas management, and arch reconstruction with deep hypothermic antegrade cerebral perfusion by way of an innominate artery shunt at $50 \mathrm{~mL} / \mathrm{kg} / \mathrm{min}$ flow with minimal circulatory arrest. Phenoxybenzamine $0.25 \mathrm{mg} / \mathrm{kg}$ was administered to all patients receiving CPB. ${ }^{37,39}$ The postoperative hemodynamic targets included the mean arterial pressure greater than $45 \mathrm{~mm} \mathrm{Hg}$, central venous pressure (CVP) 8 to $12 \mathrm{~mm} \mathrm{Hg}$, arterial oxygen saturation $\left(\mathrm{SaO}_{2}\right)$ greater than $75 \%$, superior vena cava $\mathrm{SvO}_{2}$ greater than $50 \%$, and cerebral oxygen saturation $\left(\mathrm{rSO}_{2} \mathrm{C}\right)$ greater than $50 \%$. Strategies to achieve these targets included delayed sternal closure, maintenance of normothermia $\left(36.2^{\circ}\right.$ $37.8^{\circ} \mathrm{C}$ ) using a servocontrolled warmer, sedation, and mechanical ventilation with adjustment of arterial carbon dioxide tension, transfusion of red blood cells to maintain hematocrit greater than $40 \%$, and continuous infusions of milrinone, epinephrine, and norepinephrine, as necessary. Neither buffer nor hyperventilation was used to adjust blood $\mathrm{pH}$.

\section{Physiologic Assessment}

The hemodynamic data included $\mathrm{SaO}_{2}$ (Masimo SET algorithm, Masimo Corp, Irvine Calif), $\mathrm{SvO}_{2}$ (4F Oxycath, Abbott Laboratories, Abbott Park, Ill) placed in the superior vena cava at S1P, invasive mean arterial pressure, and CVP (from the umbilical vein or common atrial line), all acquired by a standard multiparameter monitor (Solar, GE Healthcare, Milwaukee, Wis). The cerebral oxygen saturation was obtained from a right-midline forehead sensor and somatic/renal saturation from the T12-L2 somatic region using a dual-light path, continuous-wave, NIRS device (INVOS 5100A/B with a pediatric sensor, Somanetics Inc, Troy, Mich). ${ }^{31}$ These measures were continuously monitored and recorded at hourly intervals using a standardized clinical flowsheet for the first 48 hours after S1P. A laboratory assessment of the arterial and venous blood gases, including arterial carbon dioxide tension, hydrogen ion log concentration $(\mathrm{pH})$, standard base excess, and hemoglobin concentration, was obtained at clinically indicated intervals and included in the physiologic database, with linear interpolation of missing values. The derived physiologic variables were computed using standard formulas (including the cerebral arteriovenous saturation difference: $\left.\Delta \operatorname{arSO}_{2} \mathrm{C}=\mathrm{SaO}_{2}-\mathrm{rSO}_{2} \mathrm{C}\right){ }^{31,34}$

\section{Neurodevelopment Assessment}

A ND test battery was administered by a single developmental psychologist under controlled conditions. The visual-motor integration (VMI) 
abilities are important for the development of higher level integrative skills, such as handwriting, reading, written language, and math achievement. ${ }^{40-42}$ Previous work has shown that visual-motor skills are at risk of impairment in children with complex congenital heart disease. ${ }^{38,43-46}$ From these studies, including our previous finding of a strong relationship between low superior vena cava saturation during $\mathrm{S} 1 \mathrm{P}$ and later visual-motor performance, ${ }^{14}$ the Beery-Buktenica Developmental Test of Visual Motor Integration was chosen as the primary outcome measure in the present study. Additional dimensions assessed included measures of cognitive performance (Wechsler Preschool and Primary Scale of Intelligence III Matrix Reasoning Score), attention (Developmental NEuroPSYchological Assessment Visual Attention Scale), and language (Differential Ability Scales II Naming Vocabulary Test). A composite neurodevelopmental index (NDI) was constructed using equally weighted measures from all 4 dimensions after normalization to a mean \pm standard deviation (SD) of $100 \pm 15$. Standardized scores on the VMI and NDI were classified as normal (>85), low $(-1 \mathrm{SD}$ or $<85)$, and abnormal $(-2 \mathrm{SD}$ or $<70)$. The parental assessment included maternal performance on the Wechsler Abbreviated Intelligence Test. The distance to the hospital and family income were estimated by the zip code of residence.

\section{Statistical Analysis}

Descriptive data, measures, and derived parameters are expressed as the mean \pm SD if normally distributed and as the median \pm interquartile range if not, and the $5 \%$ to $95 \%$ percentiles or range. The results of estimation are expressed as the mean \pm standard error, with $95 \%$ confidence intervals. Statistical comparisons of continuous measures were performed using analysis of variance for parametric measures, or the Kruskal-Wallis test on ranks or the Kolmogorov-Smirnov test on distributions for nonparametric measures. Comparisons of proportions were done using the chi-square likelihood ratio test or the Fisher exact test, as appropriate. Statistical comparisons of independent measures repeated over time were performed using summary statistics, the between factor in analysis of variance for repeated measures, or the generalized maximum-likelihood time-series regression. ${ }^{47}$ Summary measures for cerebral oxygenation included the 48hour average, hours under cutpoints and area under curve, for thresholds of $45 \%, 50 \%$, and $55 \%{ }^{48}$ To assess the potential ascertainment bias, the demographic, treatment, and physiologic measures were compared between the subgroups that did or did not complete ND testing. To evaluate the factors related to ND outcome, subgroups with low or abnormal versus normal ND performance were compared with univariate followed by multivariate tests, and regression techniques were used across the entire tested cohort. Because previous work has demonstrated a nonlinear relationship between cerebral saturation and indexes of neurologic injury, both linear and nonlinear relationships were explored, using second- and third-order fractional polynomials and bilinear (breakpoint) regression analysis. Statistically significant physiologic parameters were then stratified at clinically appropriate thresholds to assess nonlinear relationships and entered into multivariate models using the between-patient estimator for outcome. The patient and treatment demographic factors were included in multivariate models of ND performance versus physiologic measures, using stepwise techniques with $P<.2$ for inclusion, ${ }^{49-51}$ and with constraints for selection of important biologic parameters. ${ }^{52,53}$ All tests were conducted as 2-tailed and considered statistically significant at $P<.05$ after adjustment for repeated measures within patient panels by variance correction and for multiple comparisons by Tukey's honestly significant difference or Bonferroni's method. All analyses were performed with Stata, version 11 (StataCorp 2009, College Station, Tex).

\section{RESULTS}

Of the 51 patients in the operative cohort, stage 1 operative survival (30-day or discharge) was 48 of $51(94 \%)$, and cumulative survival (to the time of study) was 44 of 51
$(86 \%)$ at $7.1 \pm 1.0$ years (range, $5.1-8.9$ years). ND testing was completed in 21 patients ( $41 \%$ of total and $48 \%$ of survivors). The demographic and treatment parameters are summarized in Table 1, for the entire operative cohort and the subgroup that completed ND testing. No significant differences were found between the tested and nontested subgroups, other than nonsurvivors requiring more time on extracorporeal membrane oxygenation. The incidence of preoperative high-risk status (prematurity, low birth weight, or other noncardiac anomalies) was 13 of $51(25 \%)$ overall, 3 of $7(43 \%)$ in nonsurvivors, and 3 of $21(14 \%)$ in tested patients $(P=\mathrm{NS})$. The physiologic parameters are summarized in Table 2 . The only differences between the tested and nontested subgroups were attributable to the duration of extracorporeal membrane oxygenation.

The mean age at testing was $56.3 \pm 5.5$ months (range, 48 66 months). Performance of the tested cohort on the BeeryBuktenica VMI test was $93.4 \pm 14$ (range, 51-114), less than the general population mean of $100(P=.043)$. Only 1 of 21 patients $(4.7 \%)$ had an abnormal VMI $(<70)$, and $3(14.2 \%)$ had a low performance $(<85)$, frequencies not different from the expected norm. Performance on the Wechsler Preschool and Primary Scale of Intelligence III Matrix Reasoning Score (cognition) and Differential Ability Scales II Naming Vocabulary Test (language) were normal, performance on the Developmental NEuroPSYchological AssessmentVisual Attention Scale (attention) was above normal, and the composite NDI was normal at $97.6 \pm 9.6$ (range, 71-109). These results are summarized in Table 3.

The average $\mathrm{rSO}_{2} \mathrm{C}$ in the first 48 postoperative hours after $\mathrm{S} 1 \mathrm{P}$ was $67.1 \pm 8.3$, lower in patients who demonstrated low or abnormal VMI performance compared with the rest of the tested cohort $\left(\mathrm{rSO}_{2} \mathrm{C} 63.6 \pm 8.1\right.$ vs $67.8 \pm 8.1, P=.026$; Figure 1 ). The low-performing patients also spent more time with a $\mathrm{rSO}_{2} \mathrm{C}$ less than the threshold of $55 \%$ and $45 \%$ (Table 4). During the first 48 postoperative hours, the $\mathrm{rSO}_{2} \mathrm{C}$ was consistently lower in patients with a low performance, the $\mathrm{SaO}_{2}$ was lower during the first 24 hours, and the mean arterial blood pressure was not different (Figure 2). Other measures related to oxygen delivery, including somatic/renal $\mathrm{rSO}_{2} \mathrm{R}, \mathrm{SvO}_{2}$, and arterial partial pressure of carbon dioxide, were not different between the subgroups.

The 21 patients with ND testing had a total of 1008 hours of physiologic data from the post-S1P period available for analysis (Table 5). Only rSO${ }_{2} \mathrm{C}$ and $\mathrm{SaO}_{2}$ were different on univariate analysis between the low or abnormal and normal VMI subgroups. The $\mathrm{rSO}_{2} \mathrm{C}, \mathrm{SaO}_{2}$, and cerebral arterial-regional saturation difference $\left(\Delta \operatorname{arSO}_{2} \mathrm{C}\right)$ were related to $\mathrm{VMI}$ in nonlinear multivariate models (Figure 3 ). The mean arterial blood pressure, CVP, hemoglobin concentration, and blood gas parameters were not significant in either analysis.

Two children had discrete and clinically evident neurologic events that occurred after their initial hospitalization 
TABLE 1. Population characteristics, according to neurodevelopmental testing and cumulative survival status

\begin{tabular}{|c|c|c|c|c|}
\hline \multirow[b]{2}{*}{ Characteristic } & \multirow[b]{2}{*}{ Overall } & \multirow[b]{2}{*}{ Nonsurvivors } & \multicolumn{2}{|c|}{ ND tested } \\
\hline & & & No & Yes \\
\hline Patients (n) & $51(100)$ & $7(14)^{*}$ & $23(45)$ & $21(41)$ \\
\hline Age at $\mathrm{S} 1 \mathrm{P}(\mathrm{d})$ & $7.9 \pm 8.2$ & $9.5 \pm 5.3$ & $8.6 \pm 11.8$ & $6.5 \pm 2.2$ \\
\hline Weight at S1P $(\mathrm{kg})$ & $3.4 \pm 0.5$ & $3.3 \pm 0.4$ & $3.4 \pm 0.6$ & $3.4 \pm 0.5$ \\
\hline Female gender (n) & $17(33)$ & $3(43)$ & $9(39)$ & $5(24)$ \\
\hline Gestational age (wk) & $38.3 \pm 1.3$ & $37.7 \pm 1.4$ & $38.5 \pm 1.3$ & $38.1 \pm 1.3$ \\
\hline Prematurity (<37 wk) (n) & $5(9)$ & $1(17)$ & $2(6)$ & $2(9)$ \\
\hline Prenatal diagnosis (n) & $29(57)$ & $4(57)$ & $15(65)$ & $10(48)$ \\
\hline Preoperative high-risk status & $13(25)$ & $3(43)$ & $7(30)$ & $3(14)$ \\
\hline Distance (ZIP code of residence, miles) & $81 \pm 87$ & $114 \pm 120$ & $83 \pm 80$ & $66 \pm 63$ \\
\hline Income (ZIP code of residence, $\mathrm{K} \$$ ) & $50 \pm 27$ & $39 \pm 22$ & $48 \pm 17$ & $52 \pm 37$ \\
\hline 30-Day survival (n) & $48(94)$ & $4(57)^{*}$ & $23(100)$ & $21(100)$ \\
\hline Preoperative mechanical ventilation (n) & $34(66)$ & $4(57)$ & $15(65)$ & $15(70)$ \\
\hline Preoperative inotropic support $(\%)$ & $22(43)$ & $4(57)$ & $9(39)$ & $9(43)$ \\
\hline Aortic atresia $(\%)$ & $25(49)$ & $5(57)$ & $11(52)$ & $9(43)$ \\
\hline Ascending aortic diameter (mm) & $3.7 \pm 1.7$ & $2.8 \pm 1.0$ & $3.5 \pm 1.8$ & $4.2 \pm 1.6$ \\
\hline Morphologic LV dominance (\%) & $7(14)$ & $2(29)$ & $3(13)$ & $2(9)$ \\
\hline RV-PA conduit procedure $(\%)$ & $20(39)$ & $5(71)$ & $9(39)$ & $6(29)$ \\
\hline Length of initial hospitalization (d) & $44.1 \pm 31.8$ & $63.6 \pm 32.5$ & $46.7 \pm 37.9$ & $34.7 \pm 19.6$ \\
\hline Oral feeding at discharge $(\mathrm{n})$ & $19(37)$ & $3(43)$ & $9(39)$ & $7(33)$ \\
\hline Interstage monitoring $(\mathrm{n})$ & $43(84)$ & $4(57) \dagger$ & $20(87)$ & $19(90)$ \\
\hline Interstage monitoring event $(\mathrm{n})$ & $24(57)$ & $2(50)$ & $9(45)$ & $11(52)$ \\
\hline ECMO use, patients (n) & $4(16)$ & $2(28)$ & $1(6)$ & $1(5)$ \\
\hline ECMO use, total hours ( $\%$ of 48 ) & $166(7)$ & $89(27)^{*}$ & $45(4)$ & $32(3)$ \\
\hline CPR performed $(n)$ & $4(8)$ & $2(28)$ & $1(4)$ & $1(5)$ \\
\hline Stroke after S1P (n) & $3(6)$ & $0(0)$ & $1(4)$ & $2(9)$ \\
\hline
\end{tabular}

Data are $\mathrm{n}(\%)$ or mean \pm SD. No differences observed between subgroups, except for lower early survival in cumulative nonsurvivor subgroup. $N D$, Neurodevelopment; $S 1 P$, stage 1 palliation; $L V$, left ventricular; $R V-P A$, right ventricle to pulmonary artery; $E C M O$, extracorporeal membrane oxygenation; $C P R$, cardiopulmonary resuscitation. $* P<.005$, different from other groups by chi-square test. $\dagger P<.05$, different from other groups by chi-square test.

(both embolic strokes, one after prestage 2 catheterization and one after Fontan palliation). These 2 children had obvious motor impairment at testing and performed significantly more poorly on VMI testing than the other patients in the tested cohort. No difference was seen in the mean hourly weighted $\mathrm{rSO}_{2} \mathrm{C}$ between patients who did or did not experience late stroke $(67.3 \pm 5.6$ vs $67.1 \pm 8.5$, $P=\mathrm{NS})$. Excluding the 2 patients with late events, the 19 patients in the no-stroke subgroup demonstrated VMI performance that was not different from normal; no patients had abnormal VMI $(<70)$, and 2 had low VMI (70-84), frequencies not different from expected in a normal population. In the no-stroke subgroup, the differences in $\mathrm{rSO}_{2} \mathrm{C}$ between patients with low and normal VMI was larger $\left(\mathrm{rSO}_{2} \mathrm{C}, 59.4 \pm 5.0\right.$ vs $\left.68.2 \pm 4.8 ; P=.026\right)$. With or without adjustment for the occurrence of later stroke, a low VMI was related to hourly measures of $\mathrm{rSO}_{2} \mathrm{C}$ less than $55 \%$ and $45 \%(P=.003$ for trend; Table 6$)$.

Patients who had any hourly $\mathrm{rSO}_{2} \mathrm{C}$ less than $45 \%$ (extreme desaturation) performed more poorly on VMI ( $79.5 \pm 9.1$ vs $94.8 \pm 13.8, P=.063$ ) and composite ND measures $(87.6 \pm 9.9$ vs $98.5 \pm 9.2, P=.094)$. These differences reached statistical significance in patients without stroke (VMI, $79.5 \pm 9.2$ vs $97.5 \pm 9.8, P=.025$; NDI, $87.6 \pm 9.9$ vs $100.1 \pm 6.7, P=.028$ ). These 2 factors (area under the curve of $\mathrm{rSO}_{2} \mathrm{C}<45 \%$ and occurrence of stroke) determined $41 \%$ of the variance in VMI and $33 \%$ of the variance in NDI (Table 7). The 4 patients identified by these 2 acquired factors had significantly worse ND performance than those without cerebral desaturation or stroke (VMI, $75.8 \pm 17.0$ vs $97.5 \pm 9.8, P<.005 ;$ NDI, $86.7 \pm 13.2$ vs $100.1 \pm 6.7$, $P<.01)$.

Nonlinear (breakpoint) univariate regression of $\mathrm{rSO}_{2} \mathrm{C}$ against the $4 \mathrm{ND}$ tests and the composite NDI revealed $\mathrm{rSO}_{2} \mathrm{C}$ thresholds in the $45 \%$ to $55 \%$ for relationships to VMI, Matrix Reasoning Score, Naming Vocabulary Test, and composite NDI performance measures. The regressions were significant for VMI, Matrix Reasoning Score, and composite NDI. These results are summarized in Table 8. The results were not significantly altered by exclusion of patients with stroke, nor were they dependent on values of $\mathrm{rSO}_{2} \mathrm{C}$ less than $45 \%$.

Multiple regression of neonatal demographic and hemodynamic parameters against childhood VMI performance revealed that hourly $\mathrm{rSO}_{2} \mathrm{C}, \mathrm{SaO}_{2}$, age at $\mathrm{S} 1 \mathrm{P}$, weight at S1P, CPB time, deep hypothermic circulatory arrest (DHCA) time, and presence of post-S1P stroke produced the best model that explained an important amount of the 
TABLE 2. Postoperative physiologic measures in all 51 patients and stratified by neurodevelopmental testing

\begin{tabular}{|c|c|c|c|c|}
\hline \multirow[b]{2}{*}{ Characteristic } & \multirow[b]{2}{*}{ Overall } & \multirow[b]{2}{*}{ Nonsurvivors } & \multicolumn{2}{|c|}{ ND tested } \\
\hline & & & No & Yes \\
\hline Patients (n) & $51(100)$ & 7 (14) & $23(45)$ & $21(41)$ \\
\hline $\mathrm{rSO}_{2} \mathrm{C}(\%)$ & $67.6 \pm 8.3$ & $71.1 \pm 8.4$ & $66.9 \pm 7.9$ & $67.1 \pm 8.3$ \\
\hline $\mathrm{rSO}_{2} \mathrm{R}(\%)$ & $78.8 \pm 7.2$ & $80.9 \pm 6.2$ & $77.4 \pm 8.0$ & $79.6 \pm 6.3$ \\
\hline $\mathrm{SaO}_{2}(\%)$ & $84.5 \pm 5.5$ & $87.8 \pm 6.7$ & $83.9 \pm 5.1$ & $84.1 \pm 5.1$ \\
\hline $\mathrm{SvO}_{2}(\%)$ & $64.3 \pm 9.3$ & $68.5 \pm 11.0$ & $63.3 \pm 9.2$ & $64.1 \pm 8.7$ \\
\hline $\mathrm{BP}(\mathrm{mm} \mathrm{Hg})$ & $51.8 \pm 5.9$ & $51.0 \pm 5.4$ & $51.0 \pm 6.5$ & $52.9 \pm 5.1$ \\
\hline CVP (mm Hg) & $9.8 \pm 2.3$ & $9.1 \pm 2.1$ & $10.0 \pm 2.5$ & $9.7 \pm 2.0$ \\
\hline HR (beats/min) & $173 \pm 16$ & $171 \pm 21$ & $172 \pm 15$ & $174 \pm 16$ \\
\hline $\mathrm{pCO}_{2}(\mathrm{~mm} \mathrm{Hg})$ & $44.3 \pm 7.0$ & $49.5 \pm 9.4^{*}$ & $44.4 \pm 6.7$ & $42.9 \pm 6.2$ \\
\hline $\mathrm{pO}_{2}(\mathrm{~mm} \mathrm{Hg})$ & $52.7 \pm 27$ & $73.8 \pm 48$ & $50.8 \pm 25$ & $50.3 \pm 21$ \\
\hline $\begin{array}{c}\text { Base excess } \\
(\mathrm{mEq} / \mathrm{L})\end{array}$ & $0.45 \pm 4.6$ & $0.27 \pm 5.0$ & $0.12 \pm 4.4$ & $0.87 \pm 4.7$ \\
\hline $\mathrm{Hb}(\mathrm{g} / \mathrm{dL})$ & $15.7 \pm 1.6$ & $15.3 \pm 1.8$ & $15.8 \pm 1.5$ & $15.8 \pm 1.6$ \\
\hline $\mathrm{Sa}-\mathrm{vO}_{2}(\%)$ & $19.9 \pm 8.6$ & $17.7 \pm 9.2$ & $20.4 \pm 8.2$ & $20.0 \pm 8.7$ \\
\hline$\Delta \mathrm{a}-\mathrm{vO}_{2}\left(\mathrm{~cm}^{3} / \mathrm{dL}\right)$ & $4.3 \pm 1.9$ & $3.7 \pm 2.0$ & $4.5 \pm 1.8$ & $4.2 \pm 1.9$ \\
\hline$\Delta \operatorname{arSO}_{2} \mathrm{C}(\%)$ & $16.8 \pm 7.9$ & $16.7 \pm 8.8$ & $16.7 \pm 7.4$ & $16.9 \pm 8.0$ \\
\hline$\Delta \operatorname{arSO}_{2} \mathrm{R}(\%)$ & $5.7 \pm 7.1$ & $6.9 \pm 6.5$ & $6.1 \pm 7.5$ & $4.6 \pm 6.8$ \\
\hline \multicolumn{5}{|c|}{ 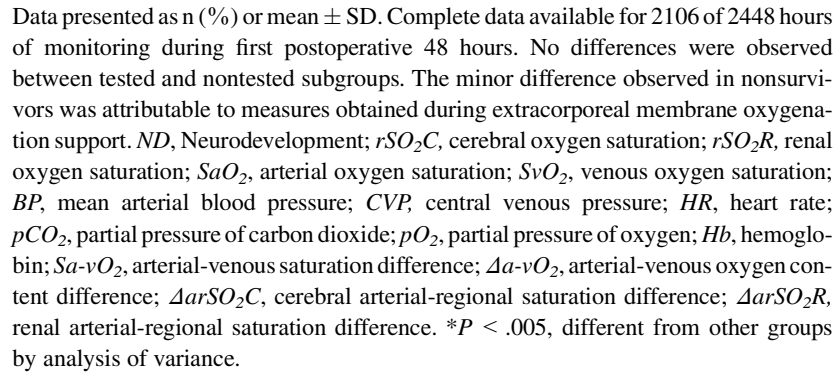 } \\
\hline
\end{tabular}

variance observed in VMI $\left(\mathrm{R}^{2}=0.53, P<.001\right.$; Table 9). The best-subset algorithm selected stroke, $\mathrm{rSO}_{2} \mathrm{C}, \mathrm{CPB}$ time, and DHCA time as the most efficient model of factors

TABLE 3. Neurodevelopmental assessment results in all 21 tested patients

\begin{tabular}{|c|c|c|c|}
\hline $\begin{array}{c}\text { ND test } \\
\text { dimension }\end{array}$ & Raw score & Normalized score & $\begin{array}{c}P \text { value } \\
\text { (compared } \\
\text { with normal) }\end{array}$ \\
\hline VMI & $93.4 \pm 14.0$ & $93.4 \pm 14.0(53-114)$ & $<.05^{*}$ \\
\hline $\begin{array}{l}\text { Cognitive } \\
\text { (WPPSI-MRS) }\end{array}$ & $9 \pm 2.9$ & $95.0 \pm 14.5(65-125)$ & NS \\
\hline $\begin{array}{l}\text { Attention } \\
\text { (NEPSY-VAS) }\end{array}$ & $11.4 \pm 1.9$ & $106.9 \pm 9.7(85-120)$ & $<.005^{*}$ \\
\hline $\begin{array}{l}\text { Language } \\
\text { (DAS-NVT) }\end{array}$ & $46.6 \pm 8.8$ & $94.9 \pm 13.2(72-117)$ & NS \\
\hline $\begin{array}{l}\text { Composite score } \\
\text { (NDI) }\end{array}$ & & $97.6 \pm 9.6(71-109)$ & NS \\
\hline \multicolumn{4}{|c|}{$\begin{array}{l}\text { Data presented as mean } \pm \text { standard deviation (range). Composite NDI scores were } \\
\text { normal compared with age-based standards. Performance was less than normal for } \\
\text { VMI, above normal for attention, and not different from normal for cognitive and lan- } \\
\text { guage dimensions. See text for details. ND, Neurodevelopmental; VMI, visual-motor } \\
\text { integration; WPPSI-MRS, Wechsler Preschool and Primary Scale of Intelligence III } \\
\text { Matrix Reasoning Score; } N S \text {, not significant; NEPSY-VAS, Developmental NEuro- } \\
\text { PSYchological Assessment Visual Attention Scale; DAS-NVT, Differential Ability } \\
\text { Scales II Naming Vocabulary Test; NDI, neurodevelopmental index. *Different } \\
\text { from population normal }(100 \pm 15) \text { by analysis of variance. }\end{array}$} \\
\hline
\end{tabular}

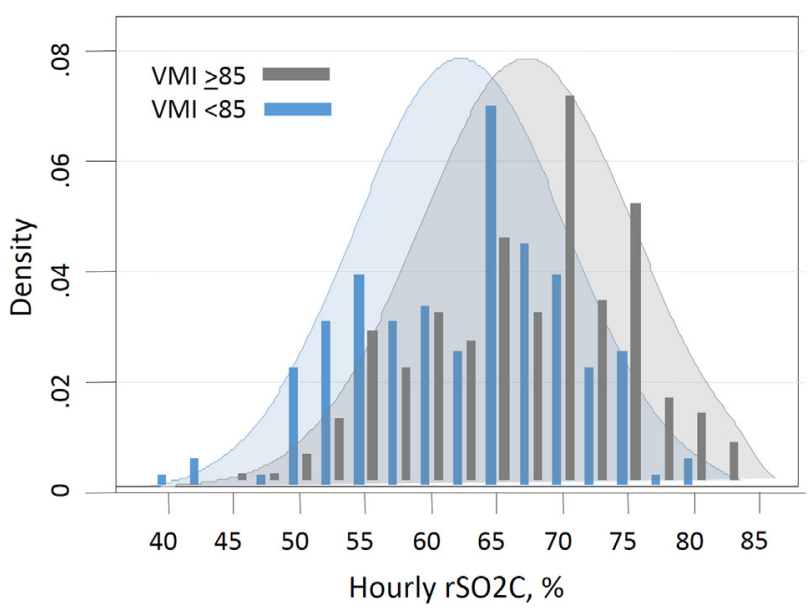

FIGURE 1. Distribution of hourly cerebral saturation $\left(\mathrm{rSO}_{2} \mathrm{C}\right)$ in patients with normal and low performance on visual-motor integration (VMI) testing. Average values and distributions were lower in patients with low VMI scores $(P<.05)$. See text for details.

related to VMI $\left(\mathrm{R}^{2}=0.50, P<.001\right)$. When controlling for factors of age and weight at S1P, CPB time, and DHCA time at their average values and the absence of post-S1P stroke, the predicted VMI was normal with an hourly $\mathrm{rSO}_{2} \mathrm{C}$ greater than $55 \%$ (Figure 4). When adjusted for all parameters at the low-risk conditions (term gestation, age at S1P of 6 days, CPB time of 120 minutes, DHCA time of 10 minutes, and no post-S1P stroke), the predicted VMI was normal until a breakpoint at an $\mathrm{rSO}_{2} \mathrm{C}$ of less than $45 \%$ (Table 10).

\section{DISCUSSION}

The composite ND performance of this cohort was normal, but the tests of VMI were slightly less than the population mean, consistent with other reported cohorts with hypoplastic left heart syndrome..$^{7,8,14,38,54,55}$ Our primary finding was that low brain oxygenation, as measured by NIRS in the early post-S1P period, was a risk factor for reduced ND performance in childhood. We have previously reported, ${ }^{14}$ using a similar study design, that $\mathrm{SvO}_{2}$ obtained from the superior vena cava after S1P, which is highly determined by cerebral oxygenation, ${ }^{15,56}$ was related to the ND outcome in early childhood. The results from the present study have corroborated those findings using a more direct and noninvasive measure of cerebral oxygenation.

Whether the low brain oxygenation measured during the first 48 postoperative hours is the actual cause of brain injury or is a marker for infants with reduced physiologic reserve and an ongoing risk of reduced cerebral oxygenation in the post-S1P period ${ }^{57,58}$ could not be determined from the present study; both relationships could be true. During the 4-year period between neonatal palliation and ND evaluation we have reported, multiple pathophysiologic processes, other than early brain hypoxia, can influence brain 
TABLE 4. Measures of cerebral oxygenation during 48 hours after S1P stratified by VMI results

\begin{tabular}{lccc}
\hline Cerebral oxygenation measure & Overall $(\mathbf{n}=\mathbf{2 1})$ & Normal VMI $(\geq \mathbf{8 5} ; \mathbf{n}=\mathbf{1 8})$ & Low VMI $(<\mathbf{8 5} ; \mathbf{n}=\mathbf{3})$ \\
\hline $\mathrm{rSO}_{2} \mathrm{C}(\%)$ & & & \\
$\quad 48$-Hour average & $67.1 \pm 8.3(40-85)$ & $67.8 \pm 8.1(42-85)$ & $63.6 \pm 8.1(40-81)^{*}$ \\
$\quad 48$-Hour minimum & $55 \pm 7.2(40-68)$ & $55.3 \pm 5.7(42-68)$ & $53.3 \pm 12(40-63)$ \\
$\mathrm{rSO}_{2} \mathrm{C}(\mathrm{h})$ & & & \\
$\quad<55 \%$ & $3.2 \pm 7.3$ & $2.5 \pm 6.2$ & $7.7 \pm 13.3 \dagger$ \\
$<50 \%$ & $0.7 \pm 2.3$ & $0.6 \pm 2.4$ & $1.3 \pm 2.3$ \\
$<45 \%$ & $0.3 \pm 0.9$ & $0.2 \pm 0.7$ & $1.0 \pm 1.7 \dagger$ \\
$\mathrm{rSO}_{2} \mathrm{C}$ AUC & & & $30 \pm 52(0-90)$ \\
$<55 \%$ & $12.6 \pm 30(0-104)$ & $9.7 \pm 27(0-104)$ & $8.3 \pm 14(0-25)$ \\
$<50 \%$ & $3.2 \pm 10(0-40)$ & $2.4 \pm 9(0-40)$ & $2.7 \pm 4.6(0-8) \ddagger$ \\
$<45 \%$ & $0.71 \pm 2.3(0-8)$ & $0.4 \pm 1.6(0-7)$ & \\
\hline
\end{tabular}

development and the occurrence of injury, including, but not limited to, patient- and center-specific management strategies, ${ }^{8}$ subsequent procedures, prolonged hospitalizations, and intercurrent events such as the 2 embolic strokes identified.

The finding that early measures of brain oxygenation have persistent effect despite multiple intervening events is evidence for the importance of hypoxic-ischemic mechanisms contributing to cerebral injury and offers the opportunity
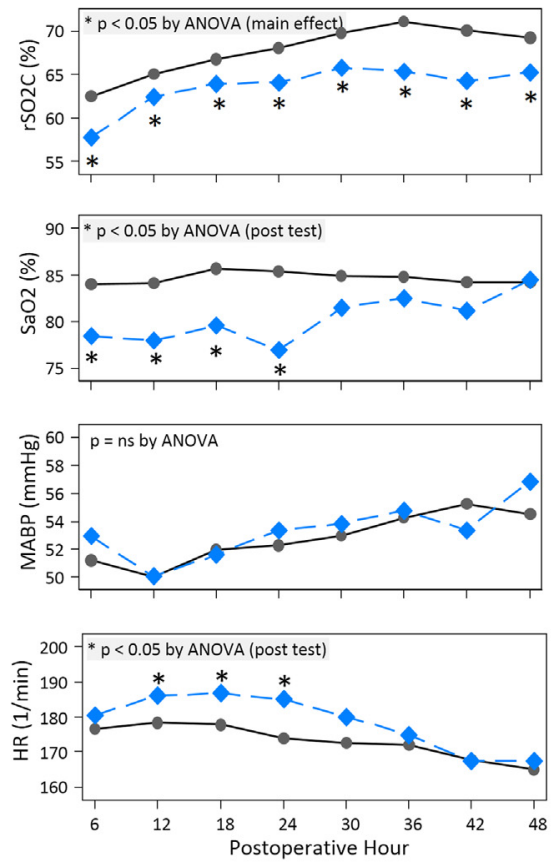

$\longrightarrow$ Normal VMI $(\geq 85)$

for treatment and prevention. In the care of the present patients, interventions to maintain $\mathrm{rSO}_{2} \mathrm{C}$ greater than $50 \%$ were a part of the perioperative management strategy and, thus, might have reduced the occurrence of cerebral hypoxia-ischemic injury, as suggested in an early report of a reduced occurrence of postoperative neurologic findings with active management of perioperative cerebral $\mathrm{rSO}_{2} \mathrm{C}^{59}$ Compared with our previously reported patient cohort managed without NIRS, the superior vena cava $\mathrm{SvO}_{2}$ in the
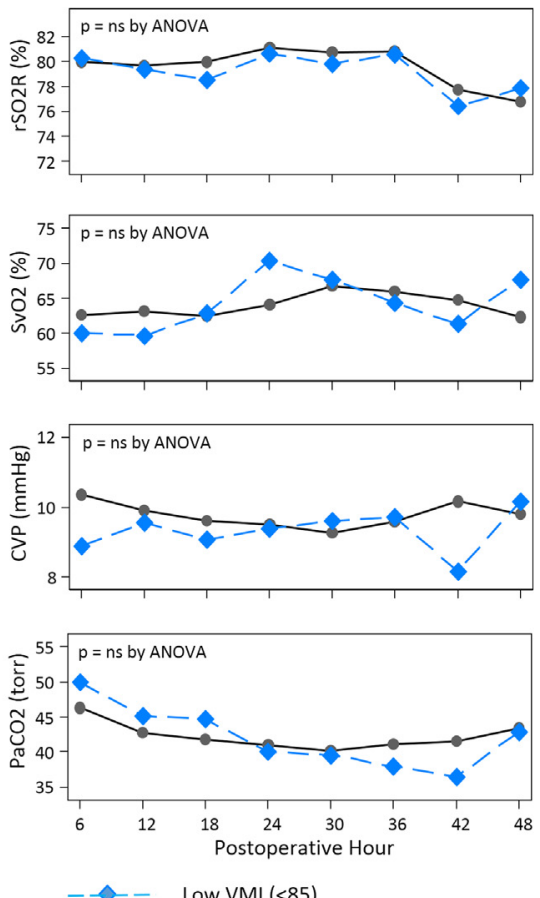

FIGURE 2. Temporal changes in early physiologic measures after stage 1 palliation $(S 1 P)$ according to performance on visual-motor integration (VMI) testing in childhood. In patients with low performance on VMI testing, cerebral saturation $\left(r \mathrm{SO}_{2} \mathrm{C}\right)$ was consistently lower during 48 postoperative hours, arterial oxygen saturation $\left(\mathrm{SaO}_{2}\right)$ lower, and heart rate $(\mathrm{HR})$ higher during first 24 hours. No differences were seen in somatic/renal saturation $\left(r \mathrm{SO}_{2} \mathrm{R}\right)$, superior vena cava oxygen saturation $\left(\mathrm{SvO}_{2}\right)$, mean arterial blood pressure $(M A B P)$, central venous/common atrial pressure $(C V P)$, or arterial partial pressure of carbon dioxide $\left(\mathrm{PaCO}_{2}\right)$. ns, Not significant; $A N O V A$, analysis of variance. 
TABLE 5. Postoperative physiologic parameters (from 1008 hours total monitoring in 21 patients) stratified by VMI results

\begin{tabular}{lccc}
\hline \multicolumn{1}{c}{ Parameter } & $\begin{array}{c}\text { Overall } \\
(\mathbf{n}=\mathbf{2 1})\end{array}$ & $\begin{array}{c}\text { Normal VMI } \\
(\geq \mathbf{8 5} ; \mathbf{n}=\mathbf{1 8})\end{array}$ & $\begin{array}{c}\text { Low VMI } \\
(<\mathbf{8 5} ; \mathbf{n}=\mathbf{3})\end{array}$ \\
\hline $\mathrm{rSO}_{2} \mathrm{C}(\%)$ & $67.1 \pm 8.3$ & $67.8 \pm 8.1$ & $63.6 \pm 8.1 *$ \\
$\mathrm{rSO}_{2} \mathrm{R}(\%)$ & $79.6 \pm 6.3$ & $79.7 \pm 6.7$ & $79.3 \pm 3.9$ \\
$\mathrm{SaO}_{2}(\%)$ & $84.1 \pm 5.1$ & $84.7 \pm 4.8$ & $80.3 \pm 5.4 *$ \\
$\mathrm{SvO}_{2}(\%)$ & $64.1 \pm 8.7$ & $64.0 \pm 8.8$ & $64.2 \pm 7.8$ \\
$\mathrm{BP}(\mathrm{mm} \mathrm{Hg})$ & $52.9 \pm 5.1$ & $52.8 \pm 5.1$ & $53.3 \pm 4.9$ \\
$\mathrm{CVP}(\mathrm{mm} \mathrm{Hg})$ & $9.7 \pm 2.0$ & $9.8 \pm 2.0$ & $9.3 \pm 1.7$ \\
$\mathrm{HR}(\mathrm{beats} / \mathrm{min})$ & $174 \pm 16$ & $174 \pm 16$ & $178 \pm 11$ \\
$\mathrm{pCO}_{2}(\mathrm{~mm} \mathrm{Hg})$ & $42.2 \pm 6.0$ & $42.2 \pm 5.9$ & $42.1 \pm 6.2$ \\
$\mathrm{pO}_{2}(\mathrm{~mm} \mathrm{Hg})$ & $46.9 \pm 5.2$ & $47.3 \pm 5.2$ & $44.4 \pm 4.7$ \\
$\mathrm{Base} \mathrm{excess}(\mathrm{mEq} / \mathrm{L})$ & $1.5 \pm 4.3$ & $1.8 \pm 4.4$ & $-0.4 \pm 3.4$ \\
$\mathrm{Hb}(\mathrm{g} / \mathrm{dL})$ & $15.9 \pm 1.4$ & $15.9 \pm 1.5$ & $15.9 \pm 1.2$ \\
$\mathrm{Sa}_{-} \mathrm{vO}_{2}(\%)$ & $20.0 \pm 8.7$ & $20.6 \pm 8.4$ & $16.2 \pm 9.5$ \\
$\Delta \mathrm{a}-\mathrm{vO}_{2}(\mathrm{~cm} / \mathrm{dL})$ & $4.4 \pm 1.8$ & $4.4 \pm 1.9$ & $3.5 \pm 2.1$ \\
$\Delta \mathrm{arSO}_{2} \mathrm{C}(\%)$ & $16.9 \pm 8.0$ & $17.0 \pm 7.9$ & $16.7 \pm 8.8$ \\
$\Delta \mathrm{arSO}_{2} \mathrm{R}(\%)$ & $4.6 \pm 6.8$ & $5.4 \pm 6.7$ & $1.1 \pm 6.1$ \\
\hline $\left.\mathrm{Da}^{3}\right)$ &
\end{tabular}

Data presented as mean \pm standard deviation. $V M I$, Visual-motor integration; $r \mathrm{SO}_{2} \mathrm{C}$, cerebral oxygenation saturation; $r \mathrm{SO}_{2} \mathrm{R}$, renal oxygen saturation; $\mathrm{SaO}_{2}$, oxygen saturation; $\mathrm{SvO}_{2}$, venous oxygen saturation; $B P$, mean arterial blood pressure; $C V P$, central venous pressure; $H R$, heart rate; $p C O_{2}$, partial pressure of carbon dioxide; $p O_{2}$, partial pressure of oxygen; $\mathrm{Hb}$, hemoglobin; $\mathrm{Sa}$ - $\mathrm{vO}_{2}$, arterial-venous saturation difference; $\triangle a-v O_{2}$, arterial-venous oxygen content difference; $\triangle a r \mathrm{SO}_{2} \mathrm{C}$, cerebral arterialregional saturation difference; $\triangle a r \mathrm{SO}_{2} \mathrm{R}$, renal arterial-regional saturation difference. $* P<.05$, different from subgroup with normal VMI, repeated measures analysis of variance.

present cohort was significantly greater $(62.6 \pm 7.88$ vs $54.4 \pm 7.85, P<.01)$ and greater than the $\mathrm{SvO}_{2}$ threshold for central nervous system injury. ${ }^{14}$ Likewise, the occurrence of VMI in the abnormally low range $(<70)$ was lower in the present cohort than in the previous cohort $(1 / 21$ vs $3 / 18$, $P=.067 ; 0 / 19$ vs $3 / 18, P<.03$, excluding late strokes). The findings within each cohort suggest that hypoxicischemic injury remains a threat to the ND potential of these patients. Comparative findings between cohorts suggest that avoidance of cerebral hypoxia by active management to avoid low $\mathrm{rSO}_{2} \mathrm{C}$ can improve outcome.

The average $\mathrm{rSO}_{2} \mathrm{C}$ was not different in patients with or without the later occurrence of stroke; therefore, it is not likely that changes in early perioperative cerebral perfusion influenced the likelihood of later stroke, especially considering the acute embolic mechanism of these events. These patients had significantly reduced performance on VMI testing, and their inclusion in the analysis complicated, but did not obscure, the relationship between the measured $\mathrm{rSO}_{2} \mathrm{C}$ values and later ND performance, again emphasizing the importance of early global hypoxic-ischemic mechanisms of injury.

The finding of a nonlinear relationship between $\mathrm{rSO}_{2} \mathrm{C}$ and VMI performance was consistent with both our previous report and other clinical and experimental studies that showed threshold effects for the dose hypoxia-ischemic conditions on cerebral injury. In normothermic ischemia models using middle cerebral artery occlusion, pixel mapping the resulting continuous range of cerebral blood flows to areas of biochemical and histologic neuronal injury allows the creation of probabilistic models of injury according to the reduction on blood flow and oxygen delivery. ${ }^{60}$ These models consistently find a threshold effect for injury, with no injury in regions with cerebral blood flow and oxygen delivery indexes greater than $50 \%$ of normal, with reversible injury in regions with flow indexes from $25 \%$ to $50 \%$ of normal, and with irreversible injury in regions with flow indexes less than $20 \%$ of normal. In piglet models of brain metabolism during acute hypoxia-ischemia monitored by NIRS, a threshold for lactate production occurred with $\mathrm{rSO}_{2} \mathrm{C}$ less than $50 \%$, and progressive neuronal dysfunction culminating in cellular death at $\mathrm{rSO}_{2} \mathrm{C}$ less than $30 \%{ }^{29}$ These thresholds occurred at NIRS-derived cerebral arteriovenous differences that were doubled or tripled, corresponding to cerebral oxygen delivery indexes that were $50 \%$ and $33 \%$ of normal, respectively. The $\mathrm{rSO}_{2} \mathrm{C}$ thresholds in the $45 \%$ to $55 \%$ range that we observed would correspond to a reduction in cerebral blood flow or oxygen delivery to the range found to induce injury in these models. Although the relationship between the time-belowthreshold and injury is complex, piglet data suggest that 1 to 2 hours of normothermic hypoxia to an $\mathrm{rSO}_{2} \mathrm{C}$ of $35 \%$ will induce acute histologic injury. ${ }^{61}$ These studies have corroborated our findings of both the degree and the duration of cerebral desaturation related to low ND performance. We emphasize that the thresholds for $\mathrm{rSO}_{2} \mathrm{C}$ in the $45 \%$ to $55 \%$ range were determined from measures that persisted for at least 1 hour in patients with reduced performance (Table 4). Automated algorithms that report nadir values might capture transient desaturations that have very small areas under curve and would be less likely to be predictive of, or result in, cerebral injury, especially with active clinical management in response to desaturation. ${ }^{62}$

The $\mathrm{rSO}_{2} \mathrm{C}$, a very close approximation of the cerebral oxygen supply-demand balance, was the physiologic parameter that was most strongly related to VMI and NDI in multivariate models. The cerebral oxygen supply is determined by perfusion pressure (mean arterial blood pressure minus CVP), $\mathrm{SaO}_{2}$, hemoglobin concentration, and cerebrovascular resistance, modifiable by partial pressure of carbon dioxide. The cerebral metabolic rate is determined by temperature and brain activity, modifiable by opioids and benzodiazepines, respectively. Changes in cerebral autoregulation after profound hypothermic bypass ${ }^{27,30,31,63-65}$ are likely to make the brain more vulnerable to supply side deficiencies and thus increasing the $\mathrm{SaO}_{2}$, hemoglobin, and partial pressure of carbon dioxide are particularly useful in the post-S1P period to increase cerebral oxygenation. These changes in autoregulation might explain our observation of a significant positive relationship of $\mathrm{SaO}_{2}$ and an apparent optimum in cerebral arterial-regional saturation difference $\left(\Delta \mathrm{arSO}_{2} \mathrm{C}\right)$ (Figure 3 ), and underlie the observation of low cerebral oxygen extraction in neonates after birth asphyxia. ${ }^{34}$ 

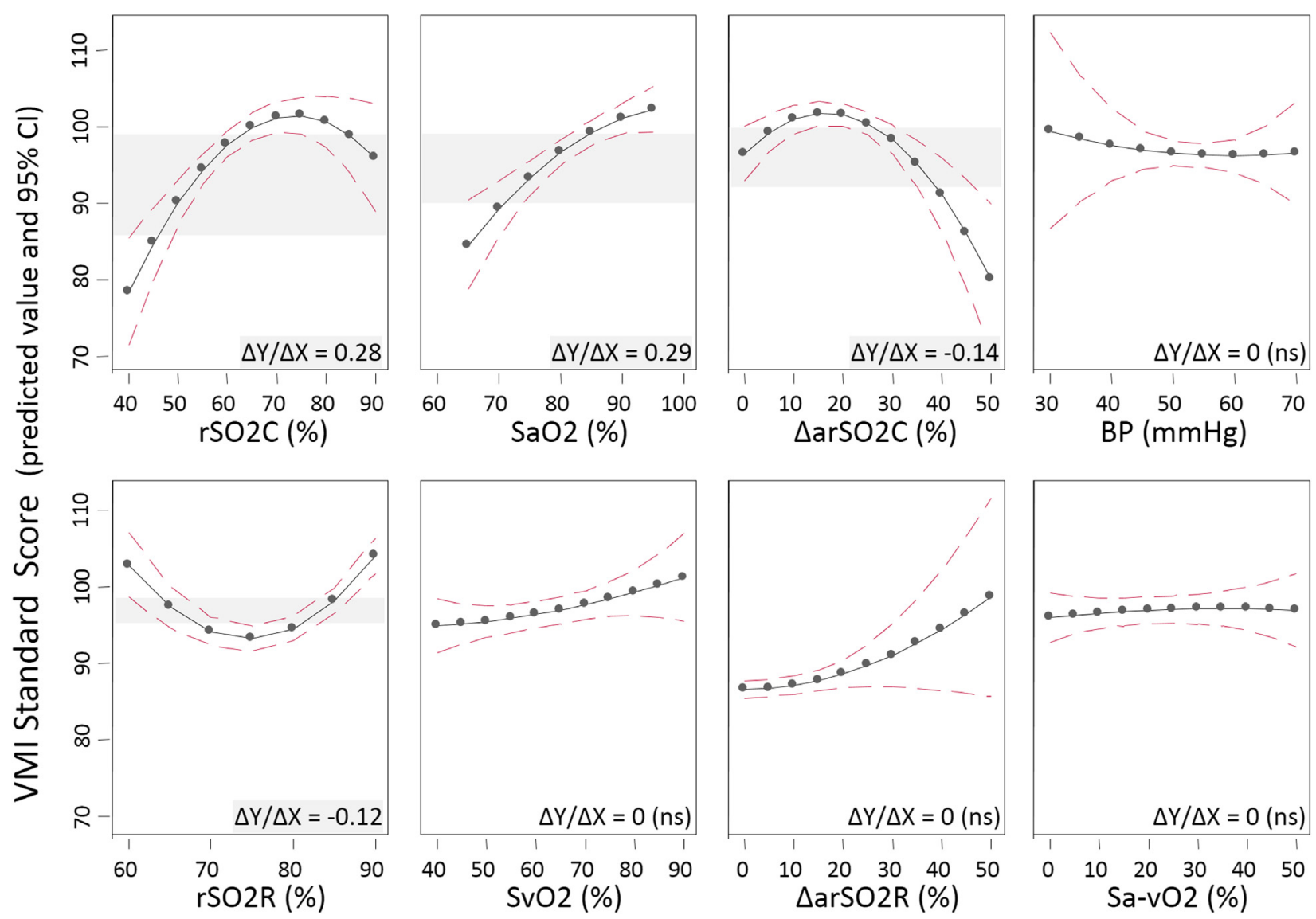

FIGURE 3. Fractional polynomial models of physiologic parameters versus visual-motor integration (VMI) performance. Magnitude of effect of each parameter estimated as difference in nonoverlapped confidence intervals of model VMI. Significant effects are depicted as gray-shaded areas. CI, Confidence interval; $\mathrm{rSO}_{2} \mathrm{C}$, cerebral oxygen saturation; $\mathrm{SaO}_{2}$, arterial oxygen saturation; $\triangle \mathrm{AarSO} \mathrm{C}_{2}$, cerebral arterial-regional saturation difference; $\mathrm{BP}$, mean arterial blood pressure; $r \mathrm{SO}_{2} \mathrm{R}$, renal oxygen saturation; $\mathrm{SavO}_{2}$, arterial-venous saturation difference; $\triangle \mathrm{arSO} \mathrm{O}_{2} \mathrm{R}$, renal arterial-regional saturation difference.

Although impaired cerebral autoregulation makes cerebral blood flow more pressure passive, ${ }^{31,66}$ manipulation of blood pressure is particularly difficult after S1P because of afterload-sensitive myocardial function and parallel circulatory anatomy, ${ }^{9,37,39}$ and maintaining high arterial $\mathrm{SaO}_{2}$ and blood pressure does not always avoid a low $\mathrm{rSO}_{2} \mathrm{C}$ after $\mathrm{S}_{1} \mathrm{P}^{30,31,56,65}$ Likewise, in the present study, we did not find evidence of a relationship between arterial blood pressure and ND performance, although our average arterial blood pressure was well above the reported lower limit of autoregulation in newborns after cardiac surgery, ${ }^{67}$ and active manipulation of all supply-side (blood pressure, partial pressure of carbon dioxide, hemoglobin concentration, arterial saturation) and demand-side factors (temperature, arousal, activity) was a part of standard perioperative management to avoid low $\mathrm{rSO}_{2} \mathrm{C}$.

The complexity of perioperative management strategies, and the interaction of intraoperative factors on postoperative cerebral hemodynamics, confounds the analysis of perioperative factors on outcomes. A study of brain injury

TABLE 6. Risk of low VMI $(<85)$ progressively increased with lower hourly $\mathrm{rSO}_{2} \mathrm{C}$

\begin{tabular}{|c|c|c|c|c|c|c|}
\hline \multirow{2}{*}{$\begin{array}{c}\text { Cerebral oxygenation } \\
\left(\text { hourly } \mathrm{rSO}_{2} \mathrm{C}\right)\end{array}$} & \multicolumn{3}{|c|}{ All tested patients $(n=21)$} & \multicolumn{3}{|c|}{ Patients without stroke $(n=19)$} \\
\hline & Frequency $(\mathbf{h})$ & Risk of low VMI $(<85)$ & $P$ value & Frequency (h) & Risk of low VMI $(<85)$ & $P$ value \\
\hline$<45 \%$ & 7 & $0.43 \pm 0.21$ & $<.05^{*}$ & 7 & $0.43 \pm 0.21$ & $<.05^{*}$ \\
\hline $46 \%-55 \%$ & 80 & $0.29 \pm 0.08$ & $<.005^{*}$ & 80 & $0.29 \pm 0.08$ & $<.005^{*}$ \\
\hline $56 \%-65 \%$ & 265 & $0.18 \pm 0.04$ & & 226 & $0.12 \pm 0.02$ & \\
\hline$>65 \%$ & 542 & $0.13 \pm 0.02$ & & 485 & $0.09 \pm 0.02$ & \\
\hline Overall & 894 & 0.16 & $<.005 \dagger$ & 798 & 0.12 & $<.005 \dagger$ \\
\hline
\end{tabular}

Data presented as mean \pm standard deviation. Risk significantly increased with $\mathrm{rSO}_{2} \mathrm{C}<45 \%$ and $46 \%-55 \%$, with and without exclusion of patients who experienced an interstage neurologic event. VMI, Visual-motor integration; $r \mathrm{SO}_{2} C$, cerebral oxygen saturation. *Risk different from overall. †Chi-square test for trend. 
TABLE 7. Linear models of neurodevelopmental outcomes $(n=21)$ as function of postoperative cerebral desaturation and interstage stroke

\begin{tabular}{lccccccc}
\hline \multicolumn{1}{c}{ Equation } & $\boldsymbol{\beta}$-rSO $\mathbf{2}_{\mathbf{2}}$ Cauc45 & $\boldsymbol{\beta}$-stroke & Constant & RMSE & $\mathbf{R}^{\mathbf{2}}$ & $\boldsymbol{F}$ & $\boldsymbol{P}$ value (overall model fit) \\
\hline VMI & $-2.5 \pm 1.1^{*}$ & $-25.6 \pm 8.5^{*}$ & $97.6 \pm 2.75$ & 11.4 & 0.411 & 6.29 & $<.005$ \\
Cognitive (WPPSI-MRS) & $-2.1 \pm 1.4$ & $-15.5 \pm 10.3$ & $100.0 \pm 3.3$ & 13.7 & 0.191 & 2.12 & $\mathrm{NS}$ \\
Attention (NEPSY-VAS) & $-0.4 \pm 1.0$ & $-2.4 \pm 7.6$ & $107.4 \pm 2.5$ & 10.1 & 0.011 & 0.10 & $\mathrm{NS}$ \\
Language (DAS-NVT) & $-2.0 \pm 1.2$ & $-14.2 \pm 9.3$ & $97.7 \pm 3.0$ & 12.5 & 0.194 & 2.17 & $\mathrm{NS}$ \\
Composite score (NDI) & $-1.7 \pm 0.8^{*}$ & $-14.4 \pm 6.2^{*}$ & $100.1 \pm 2.0$ & 8.3 & 0.331 & 4.45 & $<.05$
\end{tabular}

Model coefficients presented as $\beta \pm$ standard error. Measure of cerebral desaturation was area under curve less than threshold of $45 \%$ (rSO ${ }_{2}$ Cauc 45 ), and stroke was presence of discreet later-stage embolic event; both factors were significant determinants of ND performance, explaining $41 \%$ of VMI variance and $33 \%$ of NDI variance. The constant in each model was equal to the ND score in patients with neither $\mathrm{rSO}_{2} \mathrm{C}<45 \%$ nor interstage stroke. $r \mathrm{SO}_{2} \mathrm{Cauc} 45$, Cerebral desaturation was area under curve less than threshold of $45 \%$; RMSE, root mean square error; VMI, visual-motor integration; WPPSI-MRS, Wechsler Preschool and Primary Scale of Intelligence III Matrix Reasoning Score; NS, not significant; NEPSY-VAS, Developmental NEuroPSYchological Assessment Visual Attention Scale; DAS-NVT, Differential Ability Scales II Naming Vocabulary Test; NDI, neurodevelopmental index. $* P<.05$.

markers on magnetic resonance imaging (MRI) after neonatal cardiac surgery with high-flow antegrade cerebral perfusion and active management to avoid $\mathrm{rSO}_{2} \mathrm{C}$ less than $50 \%$ did not find a relationship between new MRI lesions and the duration of $\mathrm{rSO}_{2} \mathrm{C}$ less than $45 \% .{ }^{68}$ However, that study included both single-ventricle and 2-ventricle surgical procedures and noted a significant variation in the use of aprotinin, which might be neuroprotective and does alter the MRI findings. ${ }^{69}$ Although we would argue the undesirability of any acquired abnormalities on any assessment of brain structure or function, not all MRI lesions are ischemic in origin or indicative of permanent injury; the relationship between the postoperative MRI findings and later measures of ND performance is complex. ${ }^{68,70-73} \mathrm{~A}$ follow-up report of ND testing at 15 months ${ }^{55}$ found near-normal performance on a variety of measures, without a relationship to perioperative NIRS, although no $\mathrm{rSO}_{2} \mathrm{C}$ less than $45 \%$ was observed. Additionally, their analysis did not separate postoperative normothermic $\mathrm{rSO}_{2} \mathrm{C}$ measures from those obtained during the intraoperative period of profound hypothermia, which is likely to alter the critical $\mathrm{rSO}_{2} \mathrm{C}$ threshold for injury while increasing the $\mathrm{rSO}_{2} \mathrm{C}^{30,35,36,74,75}$ and thus obscure the relationship to outcome. Multivariate models consider additive risk constructs, and individual parameter effects will be dependent on the magnitude of other effects, especially in smaller study populations. Our analysis, with control for some confounding factors in a more homogeneous surgical population, does reveal an effect of normothermic cerebral oxygenation on later ND performance, probably related to perioperative hypoxicischemic injury. During the study period, the patients were treated using standard protocols for assessment and treatment throughout the staged reconstruction, reducing the variability in unmeasured confounders and, therefore, allowing observation of significant relationships between treatment variables and outcomes that could be obscured in other studies. ${ }^{76,77}$

The present study had several limitations. The ND assessment was completed in only $48 \%$ of the eligible cohort; thus, ascertainment bias might have influenced these findings. However, we found no differences in demographic or physiologic parameters between the tested and nontested groups (Tables 1 and 2) and that the distance from the study center was the most common reason to decline testing. The number of patients in the present analysis cohort was small, and the range of physiologic parameters and ND outcome in our cohort was narrow compared with previous cohorts. We speculated that the exposure of patients to injurious degrees of cerebral hypoxia might have been limited by management targeting $\mathrm{rSO}_{2}$ greater than $50 \%$ as a part of a cerebral goal-directed strategy, thereby reducing the incidence of very low ND performance in the present cohort. However, the persistence of a relationship between outcome and $\mathrm{rSO}_{2} \mathrm{C}$ with relatively constrained global hemodynamics only emphasizes the importance of cerebral oxygenation as an influence on ND performance. Because multiple

TABLE 8. Bilinear (breakpoint) univariate regression of cerebral oxygen saturation against later neurodevelopmental performance

\begin{tabular}{lccc}
\hline \multicolumn{1}{c}{ ND test } & $\begin{array}{c}\text { Breakpoint } \pm \text { SE } \\
\left(\mathbf{r S O} \mathbf{C}_{\mathbf{2}} \text { ) }\right.\end{array}$ & $\begin{array}{c}\boldsymbol{\beta} \text {-Coefficient } \pm \text { SE } \\
\text { (slope vs rSO } \mathbf{C} \%)\end{array}$ & $\begin{array}{c}\text { Predicted score } \\
\text { (above breakpoint) }\end{array}$ \\
\hline VMI & $56.9 \pm 2.4^{*}$ & $0.86 \pm 0.37 \dagger$ & 93 \\
Cognitive (WPPSI-MRS) & $49.2 \pm 4.7^{*}$ & $1.52 \pm 1.48$ & $<.005$ \\
Attention (NEPSY-VAS) & $55.8 \pm 42.2$ & $0.04 \pm 0.30$ & 94 \\
Language (DAS-NVT) & $62.2 \pm 2.0^{*}$ & $0.78 \pm 0.20^{*}$ & 107 \\
Composite score (NDI) & $55.8 \pm 2.6^{*}$ & $0.60 \pm 0.30 \dagger$ & 96 \\
\hline
\end{tabular}

Breakpoint was $\mathrm{rSO}_{2} \mathrm{C}$ below which a relationship between ND performance and cerebral saturation was found, with $\beta$-coefficient characterizing slope of this relationship; above the breakpoint, no relationship found with ND performance, meaning the slope was 0 . A significant model fit signified that both the breakpoint and the slope below the breakpoint were characterized. SE, Standard error; ND, neurodevelopmental; VMI, visual-motor integration; WPPSI-MRS, Wechsler Preschool and Primary Scale of Intelligence III Matrix Reasoning Score; NEPSY-VAS, Developmental NEuroPSYchological Assessment Visual Attention Scale; DAS-NVT, Differential Ability Scales II Naming Vocabulary Test; $N D I$, neurodevelopmental index; $r \mathrm{SO}_{2} C$, cerebral oxygen saturation. $* P<.001 . \dagger P<.05$. 
TABLE 9. Regression model showing relationship of cerebral oxygen saturation, physiologic and demographic variables to childhood VMI standard score

\begin{tabular}{|c|c|c|c|c|}
\hline Parameter & $\begin{array}{c}\beta- \\
\text { Coefficient } \\
\pm \mathrm{SE}\end{array}$ & $95 \% \mathrm{CI}$ & $t$ & $P$ value $>|\mathbf{t}|$ \\
\hline $\begin{array}{l}\mathrm{rSO}_{2} \mathrm{C} \\
\quad \text { (polynomial) } \%\end{array}$ & $0.11 \pm 0.04$ & $0.01,0.20$ & 2.51 & $<.05$ \\
\hline $\mathrm{SaO}_{2}-84.6 \%$ & $0.37 \pm 0.16$ & $0.010,0.030$ & 2.35 & $<.05$ \\
\hline Age at $\mathrm{S} 1 \mathrm{P}-6.8 \mathrm{~d}$ & $1.55 \pm 0.71$ & $0.06,3.04$ & 2.17 & $<.05$ \\
\hline $\begin{array}{l}\text { Weight at } \\
\text { S1P }-3.4 \mathrm{~kg}\end{array}$ & $14.2 \pm 3.8$ & $19.5,21.1$ & 3.70 & $<.005$ \\
\hline $\mathrm{CPB}$ time $-171 \mathrm{~min}$ & $-0.12 \pm 0.04$ & $-0.20,-0.03$ & -2.87 & $<.05$ \\
\hline DHCA time $-9 \min$ & $-1.34 \pm 0.59$ & $-2.57,-0.10$ & -2.26 & $<.05$ \\
\hline Stroke $(0 / 1)$ & $-23.6 \pm 8.7$ & $-33.2,-27.6$ & -2.26 & $<.05$ \\
\hline Constant & $98.1 \pm 2.4$ & $99.3,99.7$ & 41.4 & $<.001$ \\
\hline
\end{tabular}

Parameters referenced to mean value, producing constant term equal to mean predicted VMI. Factors for preoperative high-risk status (gestational age $<35$ weeks, birthweight $<2.5 \mathrm{~kg}$, associated noncardiac anomalies), maternal intelligence quotient, family income, $\mathrm{BP}, \mathrm{CVP}, \mathrm{pCO}_{2}$, and $\mathrm{Hb}$ rejected, with $P>.2$. Best between-effects time-series model: $\mathrm{R}^{2}=0.53 ; P<.001 . \quad \mathrm{rSO}_{2} \mathrm{C}$ $($ polynomial $)=\left(\mathrm{rSO}_{2} \mathrm{C}-67.3\right)-0.25 \times\left(\mathrm{rSO}_{2} \mathrm{C}-67.3\right)^{2} . V M I$, Visual-motor integration; $\mathrm{SE}$, standard error; $\mathrm{CI}$, confidence interval; $\mathrm{rSO}_{2} \mathrm{C}$, cerebral oxygen saturation; $\mathrm{SaO}_{2}$, arterial oxygen saturation; $S 1 P$, stage 1 palliation; $C P B$, cardiopulmonary bypass; $D H C A$, deep hypothermic circulatory arrest.

factors affect the occurrence of, and recovery from, cerebral injury, the postoperative normothermic thresholds for cerebral oxygenation found in the present study might be generalizable only to patients treated with similar perioperative strategies. The adoption of recent recommendations for screening and ND assessment of children with complex congenital heart disease will drive more generalizable analyses in the future. ${ }^{78}$

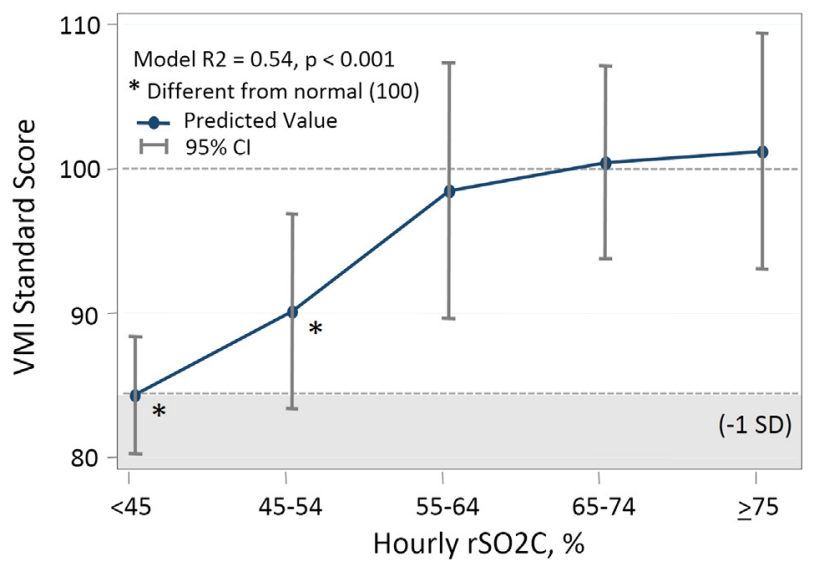

FIGURE 4. Multivariate model prediction of visual-motor integration (VMI) from hourly cerebral saturation $\left(r \mathrm{SO}_{2} \mathrm{C}\right)$. Predicted VMI was significantly lower with $\mathrm{rSO}_{2} \mathrm{C}$ less than $55 \%$. Predicted VMI was normal (not different from 100) when hourly $\mathrm{rSO}_{2} \mathrm{C}$ was maintained at greater than $55 \%$. Predicted VMI was normal with $\mathrm{rSO}_{2} \mathrm{C}$ greater than $45 \%$ and other standard risk conditions were applied. See text for details. $C I$, Confidence interval; $S D$, standard deviation.
TABLE 10. Multivariate prediction of VMI from model using categorical $\mathrm{rSO}_{2} \mathrm{C}\left(\mathrm{R}^{2}=0.54, P<.01\right)$

\begin{tabular}{lcc}
\hline Hourly $\mathbf{r S O}_{2} \mathbf{C}$ & VMI $($ model \pm SE) & $\mathbf{9 5} \% \mathbf{C I}$ \\
\hline$>75 \%$ & $103.3 \pm 1.3$ & $95.3-111.3$ \\
$66-75 \%$ & $99.9 \pm 0.8$ & $92.0-108.0$ \\
$56-65 \%$ & $98.0 \pm 1.0$ & $90.0-106.0$ \\
$46-55 \%$ & $92.2 \pm 1.8$ & $84.2-100.2$ \\
$\leq 45 \%$ & $86.3 \pm 6.1 *$ & $78.3-94.4$ \\
\hline
\end{tabular}

Model run for low-risk conditions, defined as age at S1P of 6 days, weight of $3.4 \mathrm{~kg}$, cardiopulmonary bypass time of 120 minutes, deep hypothermic circulatory arrest time of 10 minutes, and no post-stage 1 palliation stroke; under these conditions, reduced VMI performance was predicted at $\mathrm{rSO}_{2} \mathrm{C}<45 \%$, with normal VMI performance predicted at $\geq 45 \%$. VMI, Visual-motor integration; $r \mathrm{SO}_{2} \mathrm{C}$, cerebral oxygen saturation; $S E$, standard error; $C I$, confidence interval. $* P<.01$, different from 100.

\section{CONCLUSIONS}

The findings from the present report provide evidence that NIRS monitoring of brain oxygenation can help direct programmatic and patient-specific treatment strategies to detect, treat, and avoid conditions that contribute to cerebral injury. ${ }^{79-81}$ Although some determinates of outcome are not modifiable, management strategies that target brain oxygenation can reduce the burden of injury that results from cerebral hypoxia and contributes to ND impairment, allowing more children to achieve more normal outcomes.

\section{References}

1. Gaynor JW, Mahle WT, Cohen MI, Ittenbach RF, DeCampli WM, Steven JM, et al. Risk factors for mortality after the Norwood procedure. Eur J Cardiothorac Surg. 2002;22:82-9.

2. Hehir DA, Dominguez TE, Ballweg JA, Ravishankar C, Marino BS, Bird GL, et al. Risk factors for interstage death after stage 1 reconstruction of hypoplastic left heart syndrome and variants. J Thorac Cardiovasc Surg. 2008;136:94-9, e1-3.

3. Tweddell JS, Hoffman GM, Fedderly RT, Ghanayem NS, Kampine JM, Berger S, et al. Patients at risk for low systemic oxygen delivery after the Norwood procedure. Ann Thorac Surg. 2000;69:1893-9.

4. Ohye RG, Sleeper LA, Mahony L, Newburger JW, Pearson GD, Lu M, et al. Comparison of shunt types in the Norwood procedure for single-ventricle lesions. N Engl J Med. 2010;362:1980-92.

5. Gaynor JW, Wernovsky G, Jarvik GP, Bernbaum J, Gerdes M, Zackai E, et al. Patient characteristics are important determinants of neurodevelopmental outcome at one year of age after neonatal and infant cardiac surgery. J Thorac Cardiovasc Surg. 2007;133:1344-53, e1-3.

6. Tabbutt S, Nord AS, Jarvik GP, Bernbaum J, Wernovsky G, Gerdes M, et al. Neurodevelopmental outcomes after staged palliation for hypoplastic left heart syndrome. Pediatrics. 2008;121:476-83.

7. Gaynor JW, Gerdes M, Nord AS, Bernbaum J, Zackai E, Wernovsky G, et al. Is cardiac diagnosis a predictor of neurodevelopmental outcome after cardiac surgery in infancy? J Thorac Cardiovasc Surg. 2010;140:1230-7.

8. Newburger JW, Sleeper LA, Bellinger DC, Goldberg CS, Tabbutt S, Lu M, et al. Early developmental outcome in children with hypoplastic left heart syndrome and related anomalies: the single ventricle reconstruction trial. Circulation. 2012;125:2081-91.

9. Tweddell JS, Hoffman GM, Mussatto KA, Fedderly RT, Berger S, Jaquiss RD, et al. Improved survival of patients undergoing palliation of hypoplastic left heart syndrome: lessons learned from 115 consecutive patients. Circulation. 2002; 106(12 Suppl 1):I82-9.

10. Tweddell JS, Ghanayem NS, Mussatto KA, Mitchell ME, Lamers LJ, Musa NL, et al. Mixed venous oxygen saturation monitoring after stage 1 palliation for hypoplastic left heart syndrome. Ann Thorac Surg. 2007;84:1301-10.

11. Furck AK, Hansen JH, Uebing A, Scheewe J, Jung O, Kramer HH. The impact of afterload reduction on the early postoperative course after the Norwood operation-a 12-year single-centre experience. Eur J Cardiothorac Surg. 2010;37: 289-95. 
12. Furck AK, Uebing A, Hansen JH, Scheewe J, Jung O, Fischer G, et al. Outcome of the Norwood operation in patients with hypoplastic left heart syndrome: a 12-year single-center survey. J Thorac Cardiovasc Surg. 2010;139: 359-65.

13. Ghanayem NS, Hoffman GM, Mussatto KA, Frommelt MA, Cava JR, Mitchell ME, et al. Perioperative monitoring in high-risk infants after stage 1 palliation of univentricular congenital heart disease. J Thorac Cardiovasc Surg. 2010;140:857-63.

14. Hoffman GM, Mussatto KA, Brosig CL, Ghanayem NS, Musa N, Fedderly RT, et al. Systemic venous oxygen saturation after the Norwood procedure and childhood neurodevelopmental outcome. J Thorac Cardiovasc Surg. 2005;130: 1094-100.

15. Tortoriello TA, Stayer SA, Mott AR, McKenzie ED, Fraser CD, Andropoulos DB, et al. A noninvasive estimation of mixed venous oxygen saturation using nearinfrared spectroscopy by cerebral oximetry in pediatric cardiac surgery patients. Paediatr Anaesth. 2005; 15:495-503.

16. McQuillen PS, Nishimoto MS, Bottrell CL, Fineman LD, Hamrick SE, Glidden DV, et al. Regional and central venous oxygen saturation monitoring following pediatric cardiac surgery: concordance and association with clinical variables. Pediatr Crit Care Med. 2007;8:154-60.

17. Boushel R, Langberg H, Olesen J, Gonzales-Alonzo J, Bulow J, Kjaer M. Monitoring tissue oxygen availability with near infrared spectroscopy (NIRS) in health and disease. Scand J Med Sci Sports. 2001;11:213-22.

18. Booth EA, Dukatz C, Ausman J, Wider M. Cerebral and somatic venous oximetry in adults and infants. Surg Neurol Int. 2010;1:75.

19. Pollard V, Prough DS, DeMelo AE, Deyo DJ, Uchida T, Stoddart HF. Validation in volunteers of a near-infrared spectroscope for monitoring brain oxygenation in vivo. Anesth Analg. 1996;82:269-77.

20. Prough DS. Near-infrared spectroscopy. Eur J Anaesth. 1998;15:64-5.

21. Kim MB, Ward DS, Cartwright CR, Kolano J, Chlebowski S, Henson LC. Estimation of jugular venous $\mathrm{O}_{2}$ saturation from cerebral oximetry or arterial $\mathrm{O}_{2}$ saturation during isocapnic hypoxia. J Clin Monit Comput. 2000;16:191-9.

22. Abdul-Khaliq H, Troitzsch D, Berger F, Lange PE. [Regional transcranial oximetry with near infrared spectroscopy (NIRS) in comparison with measuring oxygen saturation in the jugular bulb in infants and children for monitoring cerebral oxygenation]. Biomed Tech (Berl). 2000;45:328-32.

23. Watzman HM, Kurth CD, Montenegro LM, Rome J, Steven JM, Nicolson SC. Arterial and venous contributions to near-infrared cerebral oximetry. Anesthesiology. 2000;93:947-53.

24. Kurth CD, Steven JL, Montenegro LM, Watzman HM, Gaynor JW, Spray TL, et al. Cerebral oxygen saturation before congenital heart surgery. Ann Thorac Surg. 2001;72:187-92.

25. Bernal N, Hoffman G, Ghanayem N, Arca M. Cerebral and somatic near-infrared spectroscopy in normal newborns. J Pediatr Surg. 2010;45:1306-10.

26. Johnson BA, Hoffman GM, Tweddell JS, Cava JR, Basir M, Mitchell ME, et al. Near-infrared spectroscopy in neonates before palliation of hypoplastic left heart syndrome. Ann Thorac Surg. 2009;87:571-7, 7-9.

27. Kurth CD, Steven JM, Nicolson SC, Jacobs ML. Cerebral oxygenation during cardiopulmonary bypass in children. J Thorac Cardiovasc Surg. 1997;113: 71-8, 8-9.

28. Daubeney PE, Smith DC, Pilkington SN, Lamb RK, Monro JL, Tsang VT, et al. Cerebral oxygenation during paediatric cardiac surgery: identification of vulnerable periods using near infrared spectroscopy. Eur J Cardiothorac Surg. 1998;13: 370-7.

29. Kurth CD, Levy WJ, McCann J. Near-infrared spectroscopy cerebral oxygen saturation thresholds for hypoxia-ischemia in piglets. J Cereb Blood Flow Metab. 2002;22:335-41.

30. Hoffman GM, Ghanayem NS. Perioperative neuromonitoring in pediatric cardiac surgery: techniques and targets. Progr Pediatr Cardiol. 2010;29:123-30.

31. Hoffman GM, Stuth EA, Jaquiss RD, Vanderwal PL, Staudt SR, Troshynski TJ, et al. Changes in cerebral and somatic oxygenation during stage 1 palliation of hypoplastic left heart syndrome using continuous regional cerebral perfusion. J Thorac Cardiovasc Surg. 2004;127:223-33.

32. Hoffman GM. Detection and prevention of neurologic injury in the intensive care unit. Cardiol Young. 2005;15(Suppl 1):149-53.

33. Dent CL, Spaeth JP, Jones BV, Schwartz SM, Glauser TA, Hallinan B, et al. Brain magnetic resonance imaging abnormalities after the Norwood procedure using regional cerebral perfusion. J Thorac Cardiovasc Surg. 2006;131:190-7.

34. Toet MC, Lemmers PM, van Schelven LJ, van Bel F. Cerebral oxygenation and electrical activity after birth asphyxia: their relation to outcome. Pediatrics. 2006;117:333-9.
35. McQuillen PS, Barkovich AJ, Hamrick SE, Perez M, Ward P, Glidden DV, et al Temporal and anatomic risk profile of brain injury with neonatal repair of congenital heart defects. Stroke. 2007;38(2 Suppl):736-41.

36. Kussman BD, Wypij D, Laussen PC, Soul JS, Bellinger DC, DiNardo JA, et al. Relationship of intraoperative cerebral oxygen saturation to neurodevelopmental outcome and brain magnetic resonance imaging at 1 year of age in infants undergoing biventricular repair. Circulation. 2010;122:245-54.

37. Hoffman GM, Tweddell JS, Ghanayem NS, Mussatto KA, Stuth EA, Jaquis RD et al. Alteration of the critical arteriovenous oxygen saturation relationship by sustained afterload reduction after the Norwood procedure. J Thorac Cardiovasc Surg. 2004;127:738-45.

38. Brosig CL, Mussatto KA, Kuhn EM, Tweddell JS. Neurodevelopmental outcome in preschool survivors of complex congenital heart disease: implications for clinical practice. J Pediatr Health Care. 2007;21:3-12.

39. Tweddell JS, Hoffman GM, Fedderly RT, Berger S, Thomas JP Jr, Ghanayem NS et al. Phenoxybenzamine improves systemic oxygen delivery after the Norwood procedure. Ann Thorac Surg. 1999;67:161-7, 7-8.

40. Barnhardt C, Borsting E, Deland P, Pham N, Vu T. Relationship between visualmotor integration and spatial organization of written language and math. Optom Vis Sci. 2005;82:138-43.

41. Chang SH, Yu NY. Discriminant validity of the visual motor integration test in screening children with handwriting dysfunction. Percept Mot Skills. 2009; 109:770-82

42. Sortor JM, Kulp MT. Are the results of the Beery-Buktenica Developmental Test of Visual-Motor Integration and its subtests related to achievement test scores? Optom Vis Sci. 2003;80:758-63.

43. Wypij D, Newburger JW, Rappaport LA, duPlessis AJ, Jonas RA, Wernovsky G, et al. The effect of duration of deep hypothermic circulatory arrest in infant heart surgery on late neurodevelopment: the Boston Circulatory Arrest Trial. J Thorac Cardiovasc Surg. 2003;126:1397-403.

44. Bellinger DC, Jonas RA, Rappaport LA, Wypij D, Wernovsky G, Kuban KC et al. Developmental and neurologic status of children after heart surgery with hypothermic circulatory arrest or low-flow cardiopulmonary bypass. $N$ Engl J Med. 1995;332:549-55.

45. Bellinger DC, Wypij D, du Plessis AJ, Rappaport LA, Riviello J, Jonas RA, et al. Developmental and neurologic effects of alpha-stat versus $\mathrm{pH}$-stat strategies for deep hypothermic cardiopulmonary bypass in infants. J Thorac Cardiovasc Surg 2001;121:374-83.

46. Mahle WT, Wernovsky G. Long-term developmental outcome of children with complex congenital heart disease. Clin Perinatol. 2001;28:235-47.

47. Vossoughi M, Ayatollahi S, Towhidi M, Ketabchi F. On summary measure analysis of linear trend repeated measures data: performance comparison with two competing methods. BMC Med Res Method. 2012;12:33.

48. Matthews JN, Altman DG, Campbell MJ, Royston P. Analysis of serial measurements in medical research. BMJ. 1990;300:230-5.

49. Altman DG, Andersen PK. Bootstrap investigation of the stability of a Cox regression model. Stat Med. 1989;8:771-83.

50. Derksen S, Keselman HJ. Backward, forward and stepwise automated subset selection algorithms: frequency of obtaining authentic and noise variables. $\mathrm{BrJ}$ Math Stat Psychol. 1992;45:265-82.

51. Henderson HV, Velleman PF. Building multiple regression models interactively. Biometrics. 1981;37:391-411.

52. Huberty CJ. Problems with stepwise methods: better alternatives. In: Thompson B, ed. Advances in social science methodology. Greenwich, Conn: JAI Press; 1989 43-70

53. Mundry R, Nunn CL. Stepwise model fitting and statistical inference: turning noise into signal pollution. Am Nat. 2009;173:119-23.

54. Atallah J, Dinu IA, Joffe AR, Robertson CM, Sauve RS, Dyck JD, et al. Two-year survival and mental and psychomotor outcomes after the Norwood procedure: an analysis of the modified Blalock-Taussig shunt and right ventricle-to-pulmonary artery shunt surgical eras. Circulation. 2008;118:1410-8.

55. Andropoulos DB, Easley RB, Brady K, McKenzie ED, Heinle JS, Dickerson HA et al. Neurodevelopmental outcomes after regional cerebral perfusion with neuromonitoring for neonatal aortic arch reconstruction. Ann Thorac Surg. 2012;94:1250-5.

56. Li J, Zhang G, Holtby H, Guerguerian AM, Cai S, Humpl T, et al. The influence of systemic hemodynamics and oxygen transport on cerebral oxygen saturation in neonates after the Norwood procedure. J Thorac Cardiovasc Surg. 2008; 135:83-90, e1-2.

57. Fenton KN, Lessman K, Glogowski K, Fogg S, Duncan KF. Cerebral oxygen saturation does not normalize until after stage 2 single ventricle palliation. Ann Thorac Surg. 2007;83:1431-6. 
58. Phelps HM, Mahle WT, Kim D, Simsic JM, Kirshbom PM, Kanter KR, et al. Postoperative cerebral oxygenation in hypoplastic left heart syndrome after the Norwood procedure. Ann Thorac Surg. 2009;87:1490-4.

59. Austin EH III, Edmonds HL Jr, Auden SM, Seremet V, Niznik G, Sehic A, et al. Benefit of neurophysiologic monitoring for pediatric cardiac surgery. $J$ Thorac Cardiovasc Surg. 1997;114:707-15. 17, 15-6.

60. Ginsberg MD. Adventures in the pathophysiology of brain ischemia: penumbra, gene expression, neuroprotection: the 2002 Thomas Willis Lecture. Stroke. 2003; 34:214-23.

61. Kurth CD, McCann JC, Wu J, Miles L, Loepke AW. Cerebral oxygen saturationtime threshold for hypoxic-ischemic injury in piglets. Anesth Analg. 2009;108: 1268-77.

62. Simons J, Sood ED, Derby CD, Pizarro C. Predictive value of near-infrared spectroscopy on neurodevelopmental outcome after surgery for congenital heart disease in infancy. $J$ Thorac Cardiovasc Surg. 2012;143:118-25.

63. Greeley WJ, Bracey VA, Ungerleider RM, Greibel JA, Kern FH, Boyd JL, et al. Recovery of cerebral metabolism and mitochondrial oxidation state is delayed after hypothermic circulatory arrest. Circulation. 1991;84(5 Suppl):III400-6.

64. Greeley WJ, Kern FH, Ungerleider RM, Boyd JL III, Quill T, Smith LR, et al. The effect of hypothermic cardiopulmonary bypass and total circulatory arrest on cerebral metabolism in neonates, infants, and children. J Thorac Cardiovasc Surg. 1991;101:783-94.

65. Hoffman GM. Neurologic monitoring on cardiopulmonary bypass: what are we obligated to do? Ann Thorac Surg. 2006;81:S2373-80.

66. Soul JS, Hammer PE, Tsuji M, Saul JP, Bassan H, Limperopoulos C, et al. Fluctuating pressure-passivity is common in the cerebral circulation of sick premature infants. Pediatr Res. 2007;61:467-73.

67. Brady KM, Mytar JO, Lee JK, Cameron DE, Vricella LA, Thompson WR, et al. Monitoring cerebral blood flow pressure autoregulation in pediatric patients during cardiac surgery. Stroke. 2010;41:1957-62.

68. Andropoulos DB, Hunter JV, Nelson DP, Stayer SA, Stark AR, McKenzie ED, et al. Brain immaturity is associated with brain injury before and after neonatal cardiac surgery with high-flow bypass and cerebral oxygenation monitoring. J Thorac Cardiovasc Surg. 2010;139:543-56.

69. Anttila V, Hagino I, Iwata Y, Mettler BA, Lidov HG, Zurakowski D, et al. Aprotinin improves cerebral protection: evidence from a survival porcine model. J Thorac Cardiovasc Surg. 2006;132:948-53.
70. Galli KK, Zimmerman RA, Jarvik GP, Wernovsky G, Kuypers MK, Clancy RR, et al. Periventricular leukomalacia is common after neonatal cardiac surgery. J Thorac Cardiovasc Surg. 2004;127:692-704.

71. Markowitz SD, Ichord RN, Wernovsky G, Gaynor JW, Nicolson SC. Surrogate markers for neurological outcome in children after deep hypothermic circulatory arrest. Semin Cardiothorac Vasc Anesth. 2007;11:59-65.

72. Licht DJ, Shera DM, Clancy RR, Wernovsky G, Montenegro LM, Nicolson SC, et al. Brain maturation is delayed in infants with complex congenital heart defects. J Thorac Cardiovasc Surg. 2009;137:529-37.

73. McQuillen PS. Magnetic resonance imaging in congenital heart disease: what to do with what we see and don't see? Circulation. 2009;119:660-2.

74. Dexter F, Hindman BJ. Theoretical analysis of cerebral venous blood hemoglobin oxygen saturation as an index of cerebral oxygenation during hypothermic cardiopulmonary bypass: a counterproposal to the "luxury perfusion" hypothesis. Anesthesiology. 1995;83:405-12.

75. Hagino I, Anttila V, Zurakowski D, Duebener LF, Lidov HG, Jonas RA. Tissue oxygenation index is a useful monitor of histologic and neurologic outcome after cardiopulmonary bypass in piglets. J Thorac Cardiovasc Surg. 2005;130:384-92.

76. Pasquali SK, Ohye RG, Lu M, Kaltman J, Caldarone CA, Pizarro C, et al. Variation in perioperative care across centers for infants undergoing the Norwood procedure. J Thorac Cardiovasc Surg. 2012;144:915-21.

77. Tabbutt S, Ghanayem N, Ravishankar C, Sleeper LA, Cooper DS, Frank DU, et al. Risk factors for hospital morbidity and mortality after the Norwood procedure: a report from the Pediatric Heart Network Single Ventricle Reconstruction trial. J Thorac Cardiovasc Surg. 2012;144:880-1.

78. Marino BS, Lipkin PH, Newburger JW, Peacock G, Gerdes M, Gaynor JW, et al. Neurodevelopmental outcomes in children with congenital heart disease: evaluation and management: a scientific statement from the American Heart Association. Circulation. 2012;126:1143-72

79. Tweddell JS, Ghanayem NS, Hoffman GM. Pro: NIRS is "standard of care" for postoperative management. Semin Thorac Cardiovasc Surg Pediatr Card Surg Аппи. 2010;13:44-50.

80. Hirsch JC, Charpie JR, Ohye RG, Gurney JG. Near infrared spectroscopy (NIRS) should not be standard of care for postoperative management. Semin Thorac Cardiovasc Surg Pediatr Card Surg Annu. 2010;13:51-4.

81. Mittnacht AJ. Near infrared spectroscopy in children at high risk of low perfusion. Curr Opin Anaesthesiol. 2010;23:342-7. 